\title{
An Intelligent Hydroponic Device for Astragalus membranaceus Bge. var. mongolicus (Bge.) Hsiao
}

\author{
Qiyuan Chen, ${ }^{1}$ Zhenqing Bai $\mathbb{D},{ }^{2,3}$ XiuJuan Zhang $\left(\mathbb{D},{ }^{2}\right.$ and Shengli Wang ${ }^{4}$ \\ ${ }^{1}$ Inner Mongolia Technical College of Mechanics and Electrics, Huhhot, China 010070 \\ ${ }^{2}$ Inner Mongolia Key Laboratory of Molecular Biology on Featured Plants, Inner Mongolia Academy of Science and Technology, \\ Huhhot, China 010018 \\ ${ }^{3}$ College of Life Sciences, Yan'an University, Yan'an, China 716000 \\ ${ }^{4}$ Integrated Support Center, Inner Mongolia Huhhot Science and Technology Bureau, Huhhot, China 010070
}

Correspondence should be addressed to Zhenqing Bai; shanxibzq@163.com and XiuJuan Zhang; mingyuesong@163.com

Received 5 July 2021; Accepted 17 September 2021; Published 17 November 2021

Academic Editor: Yuan Li

Copyright (C) 2021 Qiyuan Chen et al. This is an open access article distributed under the Creative Commons Attribution License, which permits unrestricted use, distribution, and reproduction in any medium, provided the original work is properly cited.

\begin{abstract}
Astragalus membranaceus Bge. var. mongolicus (Bge.) Hsiao roots are widely used as raw materials of medicine. Due to the limited arable land, cultivating medicinal plants hydroponically is increasingly concerned. However, whether the quality of $A$. membranaceus grown hydroponically is better than that produced in a field is still unknown. In this study, we designed an intelligent hydroponic device for A. membranaceus, and quality of the medicinal plant cultivated by this device was compared with that cultivated in the field. Results showed that hydroponics significantly increased effective components in A. membranaceus when compared with field. Specifically, astragaloside IV contents in A. membranaceus grown hydroponically for four weeks were higher than those cultivated in the field for two years. The biomass is not significantly different between four-week hydroponics and annual cultivation. Therefore, hydroponics with our intelligent device can be used for the sustainable production of A. membranaceus in the future.
\end{abstract}

\section{Introduction}

Astragalus membranaceus (Fisch.) Bge. is a medicinal plant which is widely used in modern medicine [1-3]. It is distributed in north China and widely cultivated in Inner Mongolia $[4,5]$. To date, the available agricultural land is decreasing in recent decades which limited the development of A. membranaceus. Facility agriculture is one of the important strategies to solve the problem of cultivated land utilization in the modern agriculture [6].

In the facility agriculture, the soilless cultivation has the advantages of saving fertilizer and water, saving labor, decreasing disease and insect, and improving high yield [6]. Among them, hydroponic nutrient mixing system can cultivate the higher-quality plant varieties [7], such as soilless cultivation of vegetables in ornamental greenhouse and the cultivation of strawberry (Fragaria $\times$ ananassa Duch.) $[8,9]$. In addition, hydroponics can quickly cultivate plants, shorten plant culture period, and improve yield. Thus, making special hydroponic device for plant growth is a determinant of sustainable plant growth and industrial development [10].

Hydroponics is a good way to produce high-yield crops by taking minimal space, makes work easier for farmers in growing of plants, and also consumes less amount of water when compared to traditional method resulting in conservation of water [11]. In production, strawberry hydroponics can avoid the occurrence of some soil-borne diseases and pests [8]. Here, an intelligent hydroponic device for cultivating $A$. membranaceus was designed.

\section{Materials and Methods}

2.1. A. membranaceus Cultivation Conditions. Seeds of A. membranaceus were collected in Chifeng City, Inner Mongolia, China, and then, seeds were sown in nutrient soils (vermiculite and nutrient soil ratio was $1: 3$ ). The seeds were 
planted with sufficient water. Then, the seedlings were cultured under $16 \mathrm{~h}$ light $/ 8 \mathrm{~h}$ darkness and $25^{\circ} \mathrm{C}$ for 30 days. Watered every two days. Then, the one-month plants were cultivated in a hydroponic device. The root of these plants was harvested in one, two, and four weeks, respectively.

For Field conditions, the seeds of $A$. membranaceus were planted directly in the field, and the plants grew for one and two years in Hohhot, Baotou, and Chifeng, Inner Mongolia. The root of $A$. membranaceus in the field was harvested with four-week hydroponic plants. Collect these roots, dry them in an oven at $45^{\circ} \mathrm{C}$, weigh, and count 10 roots. These roots were used in HPLC.

2.2. Structure of Designed Hydroponic Device. The intelligent hydroponic device is designed according to the needs of $A$. membranaceus growth. It has hydroponic tank, support seat, and support leg, which are bolted with each other; the surface of the support leg is bolted with a water pump. The water outlet end of the water pump is connected with a water injection pipe and a water extraction pipe. The water extraction pipe far away from the end of the water pump is connected with a three-way water valve. The water inlet ends at the top and bottom of the right side of the three-way water valve are, respectively, connected with a nutrition pipe and a water supply pipe. The water supply pipe away from the three-way water valve is connected with a special water pipe. Both sides of the top of the hydroponic tank are bolted with a support plate. The gap inside the support frame is penetrated with a moisture discharge pipe which is connected with a moisture discharge cover. The inner part of the fixing frame is bolted with a moisture exhaust fan. The pump operates 24 hours every work day, at $25^{\circ} \mathrm{C}$, humidity $30 \%$; the cultivate medium was modified Hoagland nutrient solution (Table 1).

2.3. High-Performance Liquid Chromatography (HPLC) Determination. Take $2.0 \mathrm{~g}$ of medicinal powder (passing through 100-mesh sieve) and accurately weigh it. Put it into a $150 \mathrm{ml}$ Soxhlet extractor, add $40 \mathrm{ml}$ methanol, soak it overnight $(12 \mathrm{~h})$, add $20 \mathrm{ml}$ methanol, and heat and reflux at $85^{\circ} \mathrm{C}$ for $4 \mathrm{~h}$. The solvent was recovered and concentrated to dryness. The residue was dissolved with $10 \mathrm{ml}$ water and shaken with water-saturated n-butanol for 4 times, $40 \mathrm{ml}$ each time. Wash thoroughly with ammonia test solution for 2 times, $40 \mathrm{ml}$ each time. Discard ammonia solution, and evaporate with $\mathrm{n}$-butanol solution. The residue was dissolved with $5 \mathrm{ml}$ water and cooled down. The residue was washed off with $50 \mathrm{ml}$ water and then eluted with $30 \mathrm{ml}$ $40 \%$ ethanol. The eluent was continued to be eluted with $80 \mathrm{ml} \mathrm{70 \%} \mathrm{ethanol.} \mathrm{The} \mathrm{eluate} \mathrm{was} \mathrm{collected} \mathrm{and} \mathrm{evaporated}$ to dryness. The residue was dissolved in methanol and transferred to $5 \mathrm{ml}$ volumetric flask; add methanol to volume to the scale, shake well, filter with $0.45 \mu \mathrm{m}$ microporous membrane, and set aside.

For the chromatographic column, Agilent Zorbax sb-c18 column $(250 \mathrm{~mm} \times 4.6 \mathrm{~mm})$ was used. The mobile phase was acetonitrile water $(32: 68)$; the flow rate was $1.0 \mathrm{ml} \cdot \mathrm{min}^{-1}$; the column temperature was $27^{\circ} \mathrm{C}$; the ELSD parameters are as follows: evaporator temperature: $112^{\circ} \mathrm{C}$, nebulizer tempera- ture: $85^{\circ} \mathrm{C}$, gas flow rate: $1.5 \mathrm{SLM}$, data rate: $80 \mathrm{~Hz}$, led intensity: $100 \%$, smoothing: 50 (5.0 seconds), and PMT gain: 10.0 ; the theoretical number of astragaloside IV was not less than $4 \mu \mathrm{l}, 10 \mu \mathrm{l}, 20 \mu \mathrm{l}$, and $10 \mu \mathrm{l}$ of the reference solution, and the test solution was, respectively, injected into the liquid chromatograph. The determination was carried out according to the above chromatographic conditions, and the HPLC liquid chromatograms were recorded.

2.4. Data Analysis. All experiments were conducted with three biological replicates. The HPLC statistical analyses data were performed using one-way ANOVA by SPSS software (version 13.0) at the significant level of $P \leq 0.01$. All figures were generated using Origin 9.0 software.

\section{Results}

3.1. The Hydroponic Device Design for A. membranaceus Cultivation. In order to alleviate the problem of land use efficiency in A. membranaceus planting, this research designs an intelligent hydroponic device for its cultivation. In the hydroponic device, a camera is fixed at the bottom of the bracket for the interior watching of the hydroponic tank. The top of the front side of the hydroponic tank is fixedly installed with a water temperature and a water level meter for the monitor of its temperature and moisture insufficiency (Figure 1). The equipment can not only reduce the staff entry but can also discharge the moist air. It can solve the problem that the current $A$. membranaceus hydroponic device still needs the staff to enter the hydroponic greenhouse for water supplement and fertilization.

3.2. The Biomass and Astragaloside IV Contents between Hydroponic Culture and Cultivation. In order to further study whether the selected cultivation has the representativeness of astragaloside IV content in the root of A. membranaceus in Inner Mongolia, three different production areas cultivation were selected for comparison. The results show that the content of astragaloside IV in hydroponic root is significantly higher than that in other areas (Figure 2(a)). At the same time, in order to understand the biomass difference between hydroponics and cultivation, their biomass was statistically analyzed. The results showed that there was significant difference between hydroponic culture, annual cultivation, and biennial cultivation (Figure 2(b)). Therefore, A. membranaceus used in this study is universal. The nutrient solution is changed every 2 weeks in the intelligent hydroponic device which can be grown continuously for 2 months of $A$. membranaceus.

3.3. The Astragaloside IV Contents Increased in Hydroponic Device Than Cultivation. To understand the cultivation status of $A$. membranaceus in hydroponic device, we blasted the astragaloside IV between the hydroponic device and filed cultivation. Interestingly, the content in hydroponic cultivation was higher than that in the field. The astragaloside IV contents is $0.218 \mathrm{mg} / \mathrm{g}$ in two years of cultivation; its content is $0.627 \mathrm{mg} / \mathrm{g}$ in two-month seedling with fourweek hydroponic cultivation (Figure 3). Meanwhile, the elapsed time of hydroponic cultivation is significantly 
TABLE 1: Hoagland nutrient formula.

\begin{tabular}{lcr}
\hline $\mathrm{Macroelements}_{3}$ & Final concentration $(\mathrm{mM})$ & Stock solution concentration (mM) \\
$\mathrm{KNO}_{3}$ & 5 & 1000 \\
$\mathrm{Ca}\left(\mathrm{NO}_{3}\right)_{2} \cdot 4 \mathrm{H}_{2} \mathrm{O}$ & 5 & 1000 \\
$\mathrm{MgSO}_{4} \cdot 7 \mathrm{H}_{2} \mathrm{O}$ & 2 & 400 \\
$\mathrm{KH}_{2} \mathrm{PO} 4$ & 1 & 200 \\
\hline $\mathrm{Microelement}$ & Final concentration $(\mu \mathrm{M})$ & Stock solution concentration (mM) \\
$\mathrm{H}_{3} \mathrm{BO}_{3}$ & 46.1 & 46.1 \\
$\mathrm{MnCl}_{2} \cdot 4 \mathrm{H}_{2} \mathrm{O}$ & 9.1 & 9.1 \\
$\mathrm{ZnSO}_{4} \cdot 7 \mathrm{H}_{2} \mathrm{O}$ & 0.76 & 0.76 \\
$\mathrm{CuSO}_{4} \cdot 5 \mathrm{H}_{2} \mathrm{O}$ & 0.32 & 0.32 \\
$\mathrm{Na}_{2} \mathrm{MoO}_{4} \cdot 2 \mathrm{H}$ & \\
\hline $\mathrm{Fe}$ & 0.24 & 0.24 \\
$\mathrm{EDTA}-\mathrm{Fe}-\mathrm{Na}$ & Final concentration $(\mu \mathrm{M})$ & \\
\hline
\end{tabular}
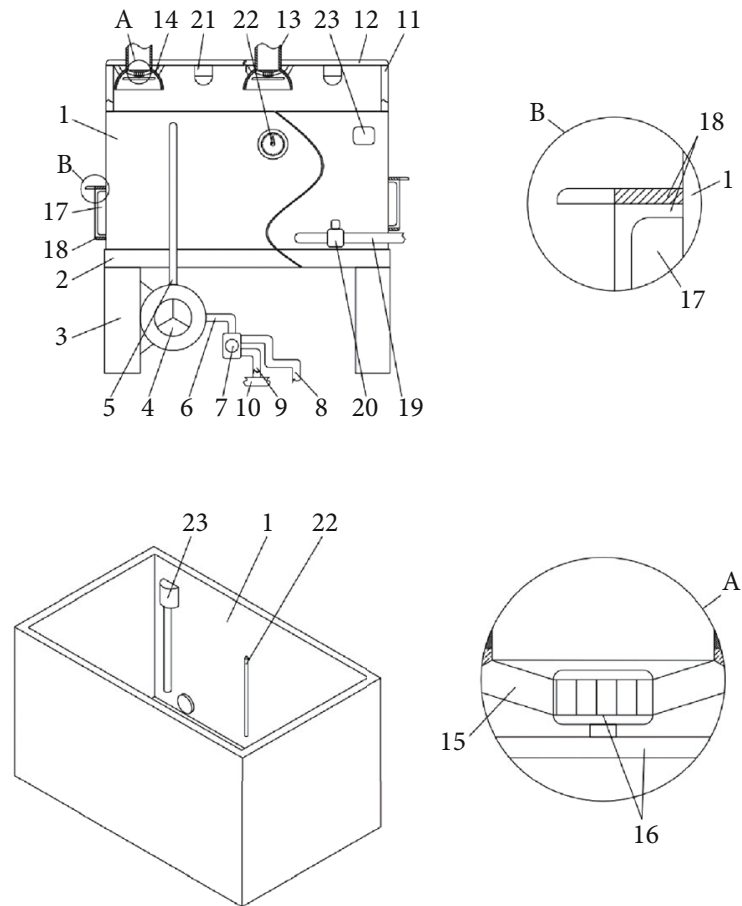

FIgURE 1: The hydroponic device structure of Astragalus membranaceus Bge. var. mongolicus (Bge.) Hsiao. An intelligent controlled Astragalus hydroponic device includes a hydroponic tank (1), a support seat (2), a support leg (3), a water pump (4), a water injection pipe (5), a water extraction pipe (6), a three-way water valve (7), a nutrition pipe (8), a water make-up pipe (9), one end of the support plate (11), a special water pipe (10), a support plate (12), the gap in the support plate (12), a moisture drainage pipe (13), a moisture drainage cover (14), a fixed pipe the inner part of the fixing frame (15), a moisture exhaust fan (16), socket (17), waterproof cover (18), drain pipe (19), drain valve (20), camera (21), water temperature gauge (22), and water level gauge (23).

shorter than that of common cultivation. From two years to two months is the significantly time efficiency improvement for A. membranaceus.

\section{Discussion}

The nutrients of plant growth come from the root absorption [12]. Field planting and indoor soil culture are common plant culture methods. At present, with the limited area of soil cultivated land in China, soilless cultivation is one of the effective ways to solve this problem [13]. The soilless cultivation technology through hydroponics, fog culture, and other ways has been widely used in vegetable and flower cultivation. The greater environmental and ecological awareness is growing the farmers who want to adopt sustainable and efficient cultivation systems [14]. Sustainable and modern cultivation systems contain cultivation devices and organic fertilization [10]. In modern agriculture, the hydroponic device is the growing process of the plant root cultivated in the nutrient-rich solutions, such as the official Real-Time Operating System (RTOS) for ARM Cortex-M microcontroller [15]. The hydroponic devices were used to produce "Biquinho" pepper with brackish water [16]. However, there are few reports on soilless cultivation of medicinal plants, such as Coptis chinensis Franch. [17]. A. membranaceus is a typical medicinal material in China. Due to the limitation of cultivated land area, developing soilless cultivation is a good way to develop plant factory production in the future [18].

In addition to the limited land use, the soil-borne disease of A. membranaceus is one of the main factors affecting its industrial development [19]. The soilless cultivation completely avoids this problem. But the frequent in and out of the equipment easily brings in foreign bacteria, which will affect the production of A. membranaceus. Moreover, the air is often humid in the hydroponic planting process, which further provides conditions for the reproduction of pathogens $[6,10]$. This A. membranaceus hydroponic device can reduce these effects on its soilless production by external visual monitoring system. Astragaloside IV is the main active component in A. membranaceus that determines its quality $[9,20,21]$. In this study, the active ingredients of four-week hydroponic cultivated 


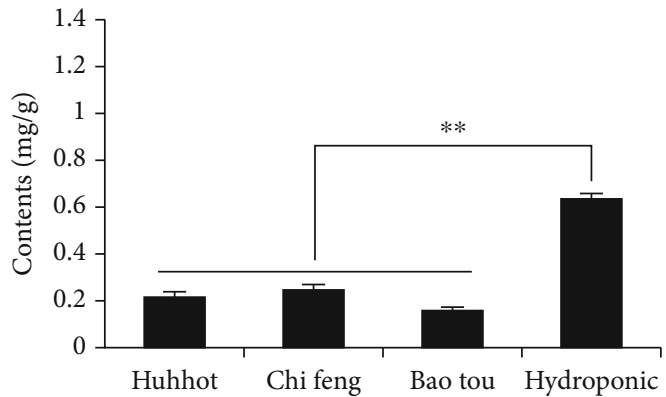

(a)

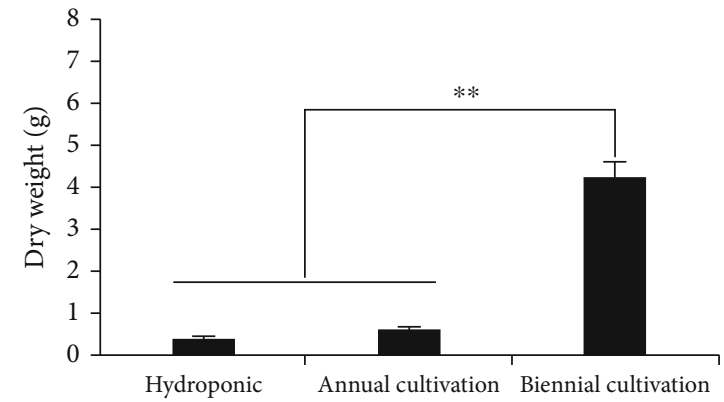

(b)

Figure 2: The astragaloside IV contents and dry weight of different cultivation areas or years in A. membranaceus Bge. var. mongolicus (Bge.) Hsiao: (a) the astragaloside IV contents of different cultivation areas in A. membranaceus Bge. var. mongolicus (Bge.) Hsiao; (b) dry weight of different years in A. membranaceus Bge. var. mongolicus (Bge.) Hsiao. Data are shown as the mean \pm SD ( $n=3$ ), and the double asterisk indicates the significance $(P<0.01)$ according to one-way ANOVA tests. The double asterisk above bars represents significant differences at the level of 0.01 .

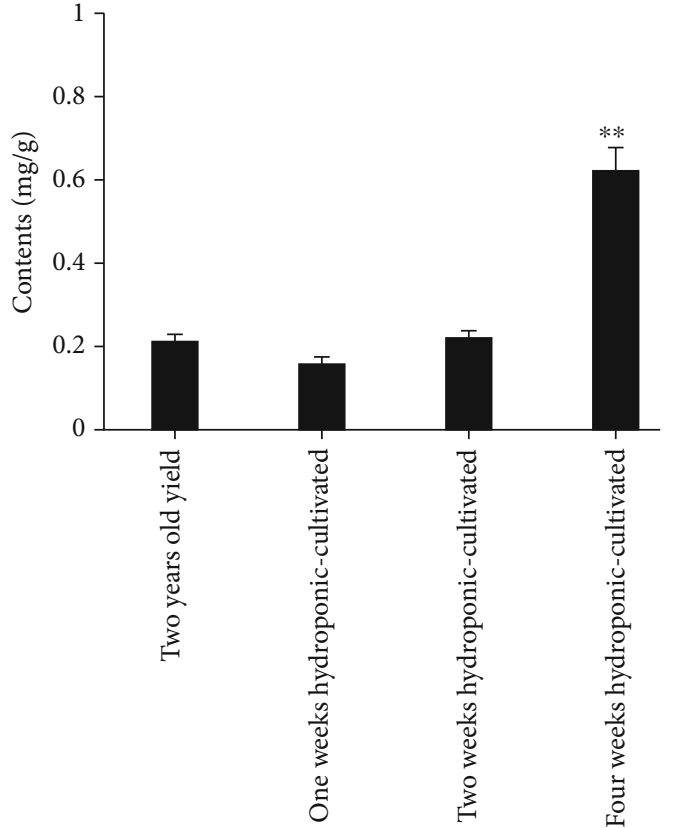

FIgUre 3: The contents of astragaloside IV in hydroponic device and yield plants. Data are shown as the mean $\pm \mathrm{SD}(n=3)$, and the double asterisk indicates the significance $(P<0.01)$ according to one-way ANOVA tests. The double asterisk above the bar represents significant differences at the level of 0.01 .

plants can reach 2 times more than those of a two-yearold field A. membranaceus. Moreover, astragaloside IV contents in Hohhot cultivation used in this study are representative. There is no difference in biomass between hydroponic and annual $A$. membranaceus, which greatly shortens its culture time and unaffected by the external environment. Meanwhile, hydroponics of A. membranaceus can realize its sustainable culture.

In conclusion, based on the soilless cultivation of $A$. membranaceus, the intelligent hydroponic device was designed to improve its cultivation efficiency and the content of active ingredients. Meanwhile, this method avoids soil- borne diseases. Soilless culture avoids continuous cropping obstacles in conventional cultivation [22]. Therefore, this study provides theoretical support for the soilless cultivation and the development of the A. membranaceus industry.

\section{Data Availability}

The data used to support the findings of this study are available from the corresponding author upon request.

\section{Conflicts of Interest}

The authors have declared no conflict of interests.

\section{Authors' Contributions}

BZQ conceived the research and wrote the manuscript. CQY performed the experiments and data analysis and revised the manuscript. ZXJ gave the project support and the design guidance of the experiment.

\section{Acknowledgments}

We thank Science and Technology Projects of Inner Mongolia Autonomous Region (2020GG0286, 2020CG0075, and 2021GG0342) for financial supports.

\section{References}

[1] M. Cheng, X. L. Chi, H. Wang, and G. Yang, "Analysis of status and problems of international trade of Astragalus membranaceus in China," Modern Chinese Medicine, vol. 21, no. 4, pp. 424-428, 2019.

[2] National Pharmacopoeia Committee, Pharmacopoeia of the People's Republic of China, China Medical Science and Technology Press, Beijing, China, 2020.

[3] Q. Zhang, Y. J. Yu, L. Jia et al., "Establishment of regenerated plantlets system from callus of Astragalus membranaceus (Fisch) Bunge," Journal of Beijing University of Agriculture, vol. 29, no. 3, pp. 18-20, 2014.

[4] S. Y. Sun and G. L. Chen, "Effects of drought stress on reproductive growth and effective components of Astragalus 
membranaceus var. mongholicus," Molecular Plant Breeding, vol. 17, no. 22, pp. 7559-7565, 2019.

[5] Y. Zhang, L. Dong, J. J. Yong, F. Y. Mao, and X. Y. Fu, "Study on the main component determination method and HPLC finger print of Radix Astragali. Lishizhen," Medicine and Materia medica Research, vol. 27, no. 11, pp. 2610-2613, 2016.

[6] M. Majid, J. N. Khan, Q. M. Ahmad Shah, K. Z. Masoodi, B. Afroza, and S. Parvaze, "Evaluation of hydroponic systems for the cultivation of Lettuce (Lactuca sativa L. , var. Longifolia) and comparison with protected soil-based cultivation," Agricultural Water Management, vol. 245, article 106572, 2021.

[7] R. Tandil, J. Yapson, W. Atmadja, S. Liawatimena, and R. Susanto, "Hydroponic nutrient mixing system based on STM32," IOP Conference Series Earth and Environmental Science, vol. 195, no. 1, article 012052, 2018.

[8] O. Grunert, E. Hernandez-Sanabria, S. Buysens et al., "Indepth observation on the microbial and fungal community structure of four contrasting tomato cultivation systems in soil based and soilless culture systems," Frontiers in Plant Science, vol. 11, 2020.

[9] L. L. Wang, H. L. Feng, K. Yang, H. M. Teng, and Z. H. Hu, "Research progress on biology and chemical constituents of Astragalus membranaceus," Genomics and Applied Biology, vol. 36, no. 6, pp. 2581-2585, 2017.

[10] G. E. Barrett, P. D. Alexander, J. S. Robinson, and N. C. Bragg, "Achieving environmentally sustainable growing media for soilless plant cultivation systems - a review," Scientia Horticulturae, vol. 212, pp. 220-234, 2016.

[11] M. S. Hariram, P. K. Kshama, M. Navaneeth, and Pratheeksha, "Fully automated hydroponics system for smart farming," International Journal of Engineering and Manufacturing (IJEM), vol. 11, no. 4, pp. 33-41, 2021.

[12] K. S. Shin, D. Chakrabarty, J. Y. Ko, S. S. Han, and K. Y. Paek, "Sucrose utilization and mineral nutrient uptake during hairy root growth of red beet (Beta vulgaris L.) in liquid culture," Plant Growth Regulation, vol. 39, no. 2, pp. 187-193, 2003.

[13] S. Nwosisi and D. Nandwani, "Urban horticulture: overview of recent developments," in Urban Horticulture. Sustainable Development and Biodiversity, vol 18, D. Nandwani, Ed., Springer, Champions, 2018.

[14] R. Altieri, A. Esposito, G. Baruzzi, and T. Nair, "Corroboration for the successful application of humified olive mill waste compost in soilless cultivation of strawberry," International Biodeterioration \& Biodegradation, vol. 88, no. 88, pp. 118-124, 2014.

[15] W. Atmadja, S. Liawatimena, J. Lukas, E. P. L. Nata, and I. Alexander, "Hydroponic system design with real time OS based on ARM cortex-M microcontroller," IOP Conference Series: Earth \& Environmental Science, vol. 109, article 012017, 2017.

[16] M. Bione, T. M. Soares, A. Cova, V. Paz, and B. Neves, "Hydroponic production of 'Biquinho' pepper with brackish water," Agricultural Water Management, vol. 245, article 106607, 2021.

[17] W. L. Huang, Z. Q. Bai, J. Jiao et al., "Distribution and chemical forms of cadmium in Coptis chinensis Franch. determined by laser ablation ICP-MS, cell fractionation, and sequential extraction," Ecotoxicology and Environmental Safety, vol. 171, pp. 894-903, 2019.
[18] R. Fan, J. Luo, S. Yan et al., "Use of water hyacinth (Eichhornia crassipes) compost as a peat substitute in soilless growth media," Compost Science \& Utilization, vol. 23, no. 4, pp. 237-247, 2015.

[19] Z. Y. Mao, H. Y. Chen, and Y. L. Li, "Effects of different cultivation modes on yield and root rot incidence rate of Astragalus membranaceus," Information of Agricultural Science and Technology, vol. 426, no. 1, pp. 52-52, 2014.

[20] Y. B. Cao, "Research progress on pharmacological activities and mechanism of astragaloside IV," Drugs \& Clinic, vol. 32, no. 5, pp. 954-960, 2017.

[21] Z. H. Sun, J. Shao, and M. Guo, "A review on chemical components and pharmacological effects of Huangqi," Clinical Journal of Chinese Medicine, vol. 7, no. 25, pp. 22-25, 2015.

[22] X. Wang, Z. Wang, and W. Zhang, "Research progress on soilless culture and nutrient solution recipes of strawberry," Tianjin Agricultural Sciences, vol. 23, no. 6, pp. 83-86, 2017. 